\title{
Vascular Leiomyoma and Geniculate Ganglion
}

\author{
Giuseppe Magliulo ${ }^{1} \quad$ Giannicola lannella ${ }^{1} \quad$ Michele Valente $^{2}$ Antonio Greco ${ }^{1}$ Mario Ciniglio Appiani ${ }^{1}$
}

1 Organi di Senso Department University “la Sapienza," Rome, Italy

2 Department of Pathology, University “la Sapienza," Rome, Italy

Address for correspondence Giuseppe Magliulo, MD, Via Gregorio VII n.80, Rome 00165, Italy (e-mail: giuseppemagliuloorl@yahoo.com).

J Neurol Surg Rep 2013;74:51-53.

\begin{abstract}
Keywords

- vascular leiomyoma

- geniculate ganglion

- surgery

- facial preservation

Objectives Discussion of a rare case of angioleiomyoma involving the geniculate ganglion and the intratemporal facial nerve segment and its surgical treatment.

Design Case report.

Setting Presence of an expansive lesion englobing the geniculate ganglion without any lesion to the cerebellopontine angle.

Participants A 45-year-old man with a grade III facial paralysis according to the HouseBrackmann scale of evaluation.

Main Outcomes Measure Surgical pathology, radiologic appearance, histological features, and postoperative facial function.

Results Removal of the entire lesion was achieved, preserving the anatomic integrity of the nerve; no nerve graft was necessary. Postoperative histology and immunohistochemical studies revealed features indicative of solid vascular leiomyoma.

Conclusion Angioleiomyoma should be considered in the differential diagnosis of geniculate ganglion lesions. Optimal postoperative facial function is possible only by preserving the anatomical and functional integrity of the facial nerve.
\end{abstract}

\section{Introduction}

Vascular leiomyoma (VL) is an uncommon benign tumor composed of smooth muscle cell and vascular endothelium. ${ }^{1}$

Intracranial involvement is quite rare: in fact, only two reports in the literature described an angioleiomyoma involving the cerebellopontine angle (CPA) and internal auditory canal (IAC). ${ }^{2,3}$

We present the case of a patient with VL localized within the geniculate ganglion and the initial labyrinthine segment of the facial nerve. To our knowledge, no other VL has been previously described in these sites.

Clinical history, imaging, histological characteristics, and surgical treatment are presented.

\section{Case Report}

In August 2012, a 45-year-old man came to our department complaining of a grade III facial paralysis (House-Brackmann scale) that had arisen 5 months earlier.

received

December 21, 2012

accepted after revision

March 10, 2013

published online

May 9, 2013

Otoscopy, as well as pure-tone audiometry, was normal with no tinnitus and no vestibular symptoms. Magnetic resonance imaging (MRI), coronal T1-weighted images revealed a hyperintense, 8-to-10-mm enhancing lesion with contrast englobing the geniculate ganglion without any alteration of the other cranial nerves. No expansive CPA lesions were present ( - Fig. $\mathbf{1}$ ).

We planned an intact canal wall tympanomastoidectomy (ICWT) with eventual facial nerve grafting. Intraoperatively, we observed a dark red mass encasing the geniculate ganglion (-Fig. 2). We were able to remove the entire lesion, identifying a cleavage plane with the geniculate ganglion and, thus, preserving the anatomical integrity of the nerve (-Fig. 3). The incus was removed during surgery. The ossiculoplasty was immediately performed modeling the incus. Postoperatively, the patient had a mild conductive hearing loss (PTA 25).

Postoperative histology showed cells of medium size with an elongated nucleus and irregular eosinophilic cytoplasm, organized in small bundles. In the context of this lesion,

(c) 2013 Georg Thieme Verlag KG Stuttgart · New York
DOI http://dx.doi.org/ 10.1055/s-0033-1346977. ISSN 2193-6358. 


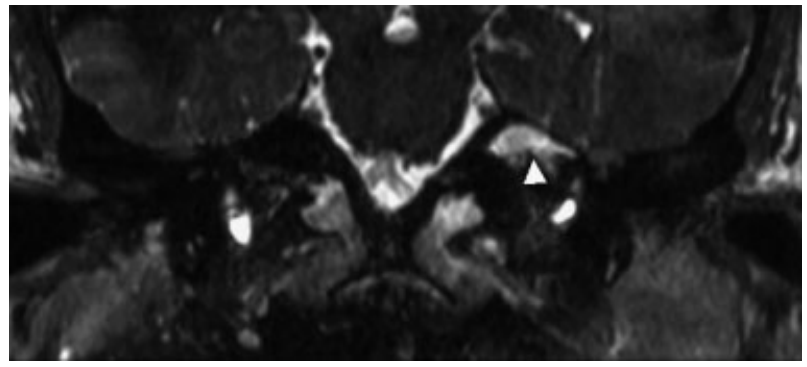

Fig. 1 Preoperative magnetic resonance imaging, coronal T1weighted images; the arrowhead indicates 8 to $10 \mathrm{~mm}$ hyperintense enhancing lesion with contrast, englobing the geniculate ganglion.

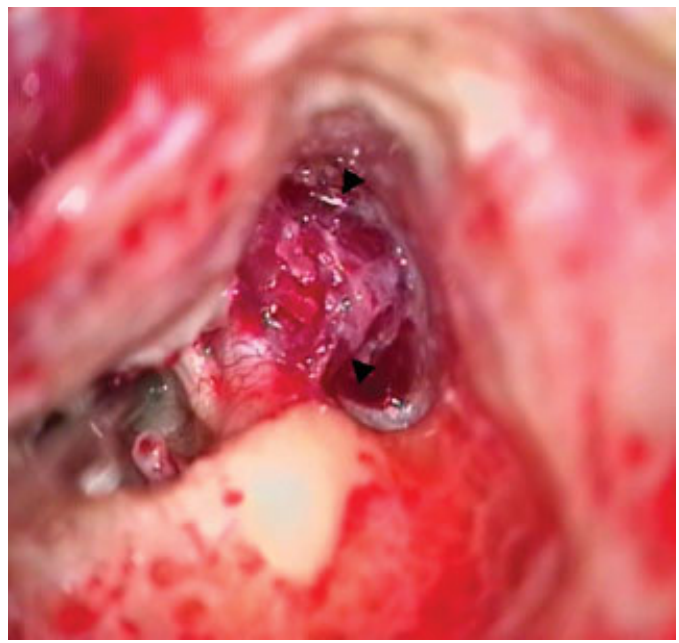

Fig. 2 Intact canal wall tympanomastoidectomy, tumor arising from the geniculate ganglion and the labyrinthine segment of the facial nerve (arrowheads).

numerous vascular spaces were evident with flat endothelium that were compressed by the lesion. Immunohistochemical studies showed abundant positivity of tumor cells for smooth muscle actin and negativity for S100. These aspects were indicative of solid VL (-Fig. 4).

At 3-month follow-up the patient was tumor-free with a recovery of the facial palsy to grade II. An MRI performed at this time confirmed the absence of any expansive lesions involving the geniculate ganglion.

\section{Discussion}

VL is a benign tumor, with vascular and smooth muscle components, first reported by Stout et al (11 cases) in $1937 .^{1}$

VL is rare in the head and neck, Wang et $\mathrm{al}^{4}$ in a study published in 2004 analyzed 160 patients with VL affecting these sites; only 21 had a tumor localization in this area. Usually, VL develops in the oral or sinonasal cavities, the parotid, submandibular region, carotid sheath, and retropharynx. Intracranially, it is very rare. Karagama et $\mathrm{al}^{2}$ and Pepper et $\mathrm{al}^{3}$ were the first to describe two cases of VL of the IAC and the CPA.

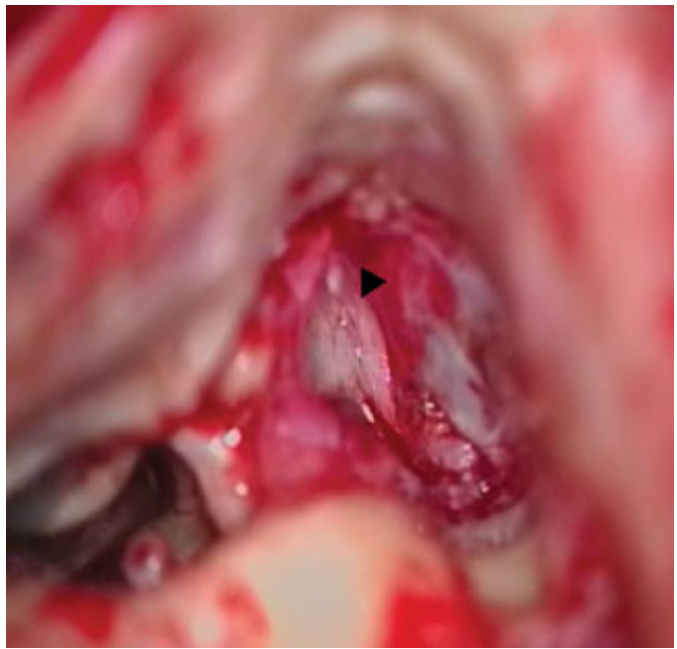

Fig. 3 Intact canal wall tympanomastoidectomy, complete removal of the lesion preserving the integrity of the nerve; the arrowhead indicates the imprint of the tumor on the geniculate ganglion.

To our knowledge, our patient is the first case of VL arising within the geniculate ganglion involving the mastoid and tympanic segment of the facial nerve.

Morimoto et $\mathrm{al}^{5}$ proposed a classification system that divides VL into three histological subtypes: capillary or solid, cavernous, and venous. Some studies have suggested that the solid subtype is the most frequent in the head and neck region. ${ }^{4}$ Microscopically, VL is generally characterized by a circumscribed nodule with well-organized smooth muscle bundles that extend in fingerlike projections from the smooth muscle in the vessel walls. The cells show eosinophilic cytoplasm and elongated basophilic nuclei with tapered endings (cigar-shaped nuclei). ${ }^{1,4,5}$ Vascular spaces, which are lined by a single layer of endothelial cells, are a constant feature in VL and have an intimate association with neoplastic cells.

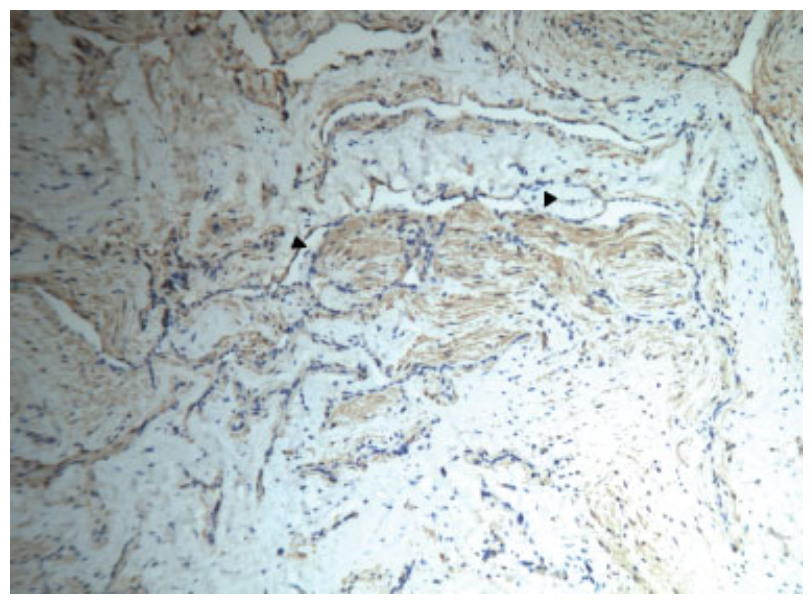

Fig. 4 Geniculate ganglion tumor; the arrowheads indicate the presence of cells with elongated nucleus, eosinophilic cytoplasm organized in small bundles; positivity for smooth muscle actin (Immunohistochemical, $10 \times$ ). 
Immunohistochemical studies were positive for musclespecific actin, desmin, and vimentin and negative for S100 protein, CD34, and CD31. ${ }^{3}$

Histological differential diagnoses include peripheral nerve sheath tumor (neurofibroma and schwannoma) and solitary fibrous tumor. ${ }^{1,3}$

Computed tomography (CT) or MRI have no specific findings for preoperative diagnosis of $\mathrm{VL}^{6}$ Mass enhancement subsequent to contrast administration, owing to the vascular nature of the lesion, might be characteristic. Therefore, only surgical removal and histological examination make it possible to establish a diagnosis with certainty.

The best treatment strategy for lesions involving the facial nerve has not yet been fully established. A conservative strategy is often adopted in the presence of normal facial nerve function or minimal preoperative dysfunction. ${ }^{7}$ In contrast, others proposed not delaying surgery at all, pointing out the increased risk for hearing loss and the better results of facial reconstruction in those patients having no facial palsy. ${ }^{8}$

When surgical management is selected, the decision regarding the surgical approach to use depends on tumor size and site. When the tumor extends from the geniculate ganglion to the tympanic segment of the nerve, as in our case, the transmastoid extralabyrinthine approach allows access to both these portions and to the beginning of the labyrinthine portion. ${ }^{9}$ Unlike our case, facial nerve integrity may be spared on rare occasions; more frequently, nerve reconstruction is required. Falcioni et $\mathrm{al}^{7}$ in a retrospective case review analyzing 28 patients undergoing surgery for primary facial nerve tumors, preserved the anatomic integrity of the nerve in 4 cases. All the others required a nerve interruption followed by immediate reconstruction using a sural nerve graft. Also, Yamaki et $\mathrm{al}^{10}{ }^{10}$ in three cases of geniculate neurinoma after removal of the lesion, achieved facial nerve reconstruction with intratemporal anastomosis of the great auricular nerve. They preferred to use the greater auricular nerve because it can be readily obtained from the neighboring anatomical field.

To conclude, angioleiomyoma should be considered in the differential diagnosis of the geniculate ganglion lesion. Our study showed that every effort should be made to preserve the anatomic and functional integrity of the facial nerve. This strategy seems to ensure the best possible postoperative facial function. ${ }^{11}$

\section{References}

1 Stout AP. Solitary cutaneous and subcutaneous leiomyoma. Am J Cancer 1937;29:435-469

2 Karagama YG, Bridges LR, van Hille PT. Angioleiomyoma of the internal auditory meatus: a rare occurrence in the internal auditory canal. Ear Nose Throat J 2005;84(4):216-218, 218

3 Pepper JP, McKeever P, Gebarski S, Spector M, Thompson BG, Arts HA. Angioleiomyoma of the internal auditory canal: clinical and radiographic features. Otol Neurotol 2010;31(9):1451-1454

4 Wang CP, Chang YL, Sheen TS. Vascular leiomyoma of the head and neck. Laryngoscope 2004;114(4):661-665

5 Morimoto N. Angiomyoma (vascular leiomyoma): a clinic-pathologic study. Med J Kagoshima Univ 1973;24:663-683

6 Magliulo G, Alla FR, Colicchio G, Trasimeni G. Geniculate ganglion meningioma. Skull Base 2010;20(3):185-188

7 Falcioni M, Russo A, Taibah A, Sanna M. Facial nerve tumors. Otol Neurotol 2003;24(6):942-947

8 Symon L, Cheesman AD, Kawauchi M, Bordi L. Neuromas of the facial nerve: a report of 12 cases. Br J Neurosurg 1993;7(1): $13-22$

9 González García JA, Arenas Brítez O, Gil Carrasco R, Lendoiro Otero C, Rodríguez Paramás A, Scola Yurrita B. [Geniculate ganglion tumors. Therapeutic and reconstructive management]. Acta Otorrinolaringol Esp 2004;55(5):206-211

10 Yamaki T, Morimoto S, Ohtaki M, et al. Intracranial facial nerve neurinoma: surgical strategy of tumor removal and functional reconstruction. Surg Neurol 1998;49(5):538-546

11 Magliulo G, D’Amico R, Forino M. Results and complications of facial reanimation following cerebellopontine angle surgery. Eur Arch Otorhinolaryngol 2001;258(1):45-48 